\title{
Em busca das raízes das nossas desigualdades sociais
}

\section{Resumo}

Análise histórica sobre o nosso direito revela legislação benéfica e integradora para com os imigrantes e descendentes no Brasil, mas também legislação omissa e muitas vezes racista para com os afrodescendentes. O advento da Constituição de 1988 com propostas integradoras possibilitará políticas de ações afirmativas.

\begin{abstract}
The analysis of brazilian law reveals a legislation with good aspects concerning the integration between immigrants and descendents, but at the same time, there is a ruling that has signs of neglection and racism to the afro-descendentes.

The promulgation of the Brazilian Constitution in 1988, with propositions benefiting integration, will allow the politics of affirmative actions.
\end{abstract}

\section{I - Introdução}

A presente pesquisa volta-se para um dos aspectos mais relevantes da questão social que envolve os brasileiros. Trata-se da desigualdade entre nosso povo, tendo como ponto alto suas origens étnicas.

É manifesto a todos, e dados oficiais confirmam, que os afrodescendentes permanecem nos extratos mais pobres da nossa pirâmide social. Têm constantemente sua situação comparada ao status dos brasileiros descendentes de imigrantes, sobretudo europeus. Ocorre que os negros bra- sileiros enfrentam discriminações lesadoras de direitos com repercussão na composição racial da pobreza.

Dados do próprio governo ("Atlas da Exclusão Social - Os Ricos do Brasil") concluem que inexiste entre nós real distribuição da riqueza e a concentração das rendas encontra-se em torno de apenas 2,4\% das famílias brasileiras.

Cabe portanto às prestações positivas do Estado assegurarem a sobrevivência de quase 90\% dos cidadãos brasileiros, cujas condições de vida comprometem a personalidade e a dignidade.

Todavia, as análises devem iniciar pelas estatísticas governamentais.

Com base em informações dos Censos de 1980 e 2000, o "Atlas da Exclusão Social - Os Ricos no Brasil", coordenado pelo professor Márcio Pochmann (Secretário do Trabalho da Prefeitura de São Paulo) e com a colaboração de economistas e pesquisadores das universidades USP, UNICAMP, PUC-SP e UNIP, esclarecem, por exemplo, que nossa concentração de rendas é histórica, pois o Censo de 1872 mostra que havia 23,4 mil famílias ricas no país, 1,8\% do total de famílias e que respondiam por dois terços da riqueza do Brasil. Já em 1920 o tal percentual é de $1,3 \%$ e hoje $2,4 \%$.

Não se tem exatamente escassez de recursos, mas desigualdade na distribuição dos bens.

Em reflexão profunda, o professor Ricardo Henriques, do Instituto de Pesquisa Econômica Aplicada (IPEA), sugere seja priorizada na questão socioeconômica a desigualdade entre brasileiros e negros: "a intensa desigualdade racial

\footnotetext{
* Professora Doutora da Faculdade de Direito da Universidade de São Paulo. Coordenadora do Núcleo de Pesquisa e Estudos Luterdisciplinar sobre o Negro Brasileiro da USP - NEINB/USP. Vice Diretora da Escola Superior da OAB/SP. Diretora executiva da Fundação PROCON. Professora do Curso de Direito das Faculdades Integradas "Campos Salles".
} 
brasileira, associada a formas usualmente sutis de discriminação racial, impede o desenvolvimento das potencialidades e o progresso social da população negra. O entendimento dos contornos econômicos e sociais da desigualdade entre os brasileiros brancos e brasileiros afrodescendentes apresenta-se como elemento central para se construir uma sociedade democrática" (op.cit.p.2).

Em entrevista para a Folha de São Paulo, de 2 de abril de 2004 (sexta-feira), p. B6 (Folha Dinheiro, jornalistas Fátima Fernandes e Claudia Rolli), o professor Márcio Pochmann afirma que o Brasil não foi capaz de distribuir as riquezas:

"Não fizemos as reformas necessárias, como outros países. Apesar dos cinco séculos de existência, não temos nem 50 anos de democracia consolidada. As instituições que representam os interesses das diversas camadas da sociedade são frágeis. "Isso mostra que houve estabilidade no padrão de distribuição de riqueza do país. A diferença é que o país passou do padrão de riqueza fundiária do século XXVIII para a riqueza da indústria e, mais recentemente, para a financeira".

Quanto aos afrodescendentes, os dados esclarecem que formam $46 \%$ dos brasileiros, mas apenas 8,7 dos ocupados em famílias de alta renda são negros ou pardos.

Tais informações devem ser apuradas também sob o ponto de vista legal.

\section{II - Quem foi Integrado pelo Direito?}

Não há como comparar os brasileiros descendentes dos imigrantes com os afrodescendentes. A história da descendência européia no Brasil é traçada por políticas de inclusão, enquanto a história da desceñđência africana é marcada pela exclusão e pela omissão. A legislação analisada leva a estas conclusões.

A) - A Lei da Terra, Lei no 601 de 18 de setembro de 1850 , definiu posições entre os imigrantes, seus descendentes e os afrodescendentes.

Observe-se o preâmbulo da mencionada Lei no $601 / 1850$ :

"Dispõem sobre as terras devolutas no Império, acerca das que são possuídas por título de sesmaria sem preenchimento das condições legais, bem como por simples título de posse mansa e pacífica; e determina que, medidas e demarcadas as primeiras, sejão elas cedidas a título oneroso, assim para empresas particulares, como para o estabelecimento de Colônias de nacionais e estrangeiros, autorizando o governo a promover a colonização estrangeira na forma que se declara".

A intenção de alcançar os imóveis ocupados pelos negros é evidente.

A exigência contida no artigo $1^{\circ}$ já exclui os afrodescendentes:

"Ficão proibidas as aquisições de terras devolutas por outro título que não seja o de compra".

A atuação do legislador é simplesmente incrível. Exclui o afrodescendente sem falar da questão racial ou da escravidão; por outro lado, o texto possui caráter benéfico e social ao garantir a posse mansa e pacífica, além de regularizar e reavaliar as sesmarias ou outras concessões do Governo. Se quisessem resolver a questão do afrodescendente, era o momento! $\mathrm{O}$ artigo 5o dizia:

"Serão legitimadas as posses mansas e pacíficas adquiridas por ocupação primária, ou havidas do primeiro ocupante, que se acharem cultivadas, ou com princípio de cultura, e a morada habitual do respectivo posseiro, ou de quem represente...".

Ora, a ocupação de terras por quilombos nunca foi interpretada como "mansa e pacífica", a despeito de os principais quilombos durarem décadas e serem numerosos. Uma segunda ou terceira geração de brasileiros, nascidos nos quilombos, já cumpririam as exigências legais. A organização econômica dos quilombos compreendia o cultivo da terra, criação de animais, com venda ou troca do excedente para vilas e fazendas próximas. A exigência "terra cultivada" e "moradia habitual" estava cumprida. Ocorre que a intenção era justamente retomar terras ocupadas pelos negros, fossem quilombos, fossem povoações de pobres libertos.

Quanto ao imigrante, a lei é benéfica, a intenção é integrá-lo, recebê-lo como trabalhador livre e aceitá-lo como proprietário. Os artigos 17 e 18 completam: 
"Art. 17 - Os estrangeiros que comprarem terras, e nellas se estabelecerem, ou viverem à sua custa exercendo qualquer indústria no Paiz, serão naturalisados querendo, depois de dois annos de residência pela fórma porque o foram os da Colônia de São Leopoldo, e ficarão isentos do serviço militar, menos do da Guarda Nacional dentro do Município".

"Art. 18 - O Governo fica autorisado a mandar vir annualmente à custa do Thesouro, certos números de colonos livres para serem empregados, pelo tempo que for marcado, em Estabelecimentos agrícolas, ou nos trabalhos dirigidos pela Administração publica, ou na formação de Colônias nos lugares em que estas mais convierem; tomando anticipadamente as medidas necessárias para que taes colonos achem emprego logo que desembarcarem. Aos colonos assim importados são applicaveis as disposições do artigo antecedente".

O "colono importado" era o imigrante, aqui equiparado para fins de aquisição de terras ao comprador estrangeiro, providência que muito contribuiu para o desenvolvimento dos grupos imigrantes no Brasil. As demais leis, como se verá, apenas complementarão a integração.

Referimo-nos à singularidade, pois, em pleno Brasil escravista, nossas pesquisas apontam as primeiras experiências integradoras com início na política imigratória desenvolvida.

B) - $O$ primeiro ato oficial sobre o estabelecimento de estrangeiros foi o Decreto de 25/11/1808 do então Príncipe Regente D. João VI:

"Permito a concessão de sesmarias aos estrangeiros residentes no Brasil.

Sendo conveniente no meo real serviço e ao bem público, aumentar a lavoura e a população, que se acha muito diminuída neste estado, e por outros motivos que me foram presentes: Hei por bem, que os estrangeiros residentes no Brasil que se possam conceder datas de terras por sesmarias pela forma, com que segundo minhas reais ordens se concedem aos meus vassalos, sem embargo de quaisquer leis ou disposições em contrário. A Mesa do Desembargo do Paço o tenha assim entendido e o faça executar. Palácio do Rio de Janeiro, em 26/11/1808".

A legislação é extensa, com leis protegendo a vida, os pertences, dispondo sobre a instalação de suas famílias. Seguem-se as leis sobre verbas públicas para a organização dos serviços e admissão de pessoal para atendimento das famílias imigrantes. As referências ao núcleo social básico (família) e o caráter desta legislação demonstram o "espírito da lei", acolhimento, atendimento e integração à vida brasileira.

C) - Destaca-se ainda nesta legislação:

"Carta Régia de 23 de setembro de 1811, dispõe sobre o início de uma colonização irlandesa na capitania do Rio Grande de São Pedro do Sul.

Decreto de 6 de maio de 1828 que autoriza a compra da Fazenda Morro Queimado, em Cantagalo, para o estabelecimento da colônia de suíços ( $f u$ tura cidade de Nova Friburgo), atendia à Carta Régia do Cantão de Friburgo (2 de maio de 1818), que solicitara o envio de famílias para o reino do Brasil".

Logo após ser constituído Príncipe Regente, D. Pedro já havia concedido, pelo Decreto de 2 de junho de 1821, uma légua de terras a Sebastião Nicolau Gachet (suíço do Cantão de Friburgo) para o estabelecimento de "engenheiros industriosos".

D) - Decisão no 80 , de 31 de março de 1824 , manda que se estabeleça uma colônia de alemães no sul do Brasil, que, posteriormente, tomou o nome de Colônia Alemã de São Leopoldo:

"Esperando brevemente nesta corte uma colônia de alemães, a qual não pode deixar de ser reconhecida de utilidade para este império, pela superior vantagem de se empregar gente branca livre e industriosa...".

O governo imperial, a exemplo do governo régio, concedia aos europeus, que aqui se estabelecessem, toda a atenção, inclusive ajuda financeira. É o que se observa no Decreto de 20 de abril de 1824, que abona subsídios pelo tempo de dois anos a colonos alemães que se estabeleçam em Nova Friburgo, dando-lhes no primeiro ano 160 réis diários e no segundo 80 réis.

E) - Carta Imperial de 24 de maio de 1824 criava o cargo de Inspetor de Colonização estrangeira na Província do Rio de Janeiro, com as seguintes atribuições: receber os colonos, cuidar do seu arranjamento, dirigir a administração dos colonos, especialmente em Nova Friburgo, ficando o diretor interino obrigado a participar-lhes to- 
das as providências para cuidar dos negócios dos imigrantes.

É importante notar que a cultura de origem do imigrante era respeitada e a presença de líderes religiosos entre os colonos dava-lhes confiança no futuro.

F) - Decreto de 11 de março de 1825 elevava a 400\$000 anuais a gratificação concedida ao Pastor da Colônia Alemã de Nova Friburgo. Os padres católicos, bem como os pastores protestantes, funcionavam como professores e árbitros entre os colonos.

$\mathrm{Na}$ realidade, as províncias e empresas privadas é que organizavam as colônias; ao governo central cabia auxiliá-las e legalizá-las. Por exemplo, a Cia. Belgo Brasileira de Colonização obteve em 1842 a concessão de terras localizadas na Província de Santa Catarina para lá estabelecer famílias belgas e alemãs.

G) - Outra legislação que demonstra o trabalho efetuado pelas empresas particulares na fundação de colônias, bem como o ânimo do governo em extinguir gradativamente a escravidão, é o Decreto no $\mathbf{5 3 7}$, de 15 de maio de 1850 , que aprova contrato realizado pela província de Santa Catarina e a Sociedade Colonizadora de Hamburgo, para fundação de colônia:

"É proibido absolutamente o emprego de braços escravos na colônia, assim como a venda e retalho de bebidas espirituosas. Estas proibições serão fiscalizadas pelo direito da colônia (salvo o direito que compete ao governo), que poderá conceder uma tal venda das ditas bebidas nos casos de necessidade, porém com as cautelas e restrições convenientes para se evitar o abuso".

H) - Neste contexto encontramos talvez nossa mais antiga discriminação positiva. Os primeiros imigrantes não eram católicos e, na vigência da Constituição de 1824, que consagrava a Igreja Católica Apostólica Romana como religião oficial do Império e restringia a prática de cultos protestantes, foi criada a Lei de 11 de janeiro de $\mathbf{1 8 6 1}$, ratificada por Decreto de 17 de abril de 1863, reconhecendo os casamentos celebrados pelos pastores protestantes.

Dessa forma protegeu-lhes as famílias e legiti- mou os filhos daqueles imigrantes, integrando-os à sociedade e aos direitos a bens de família.

I) - A primeira legislação da república referente à imigração foi o Decreto $\mathbf{n}^{\mathbf{0}} \mathbf{5 2 8}$, de 28 de junho de 1890 , onde o governo republicano delineia sua política imigratória:

"O generalíssimo Manoel Deodoro da Fonseca, chefe do governo provisório da República dos Estados Unidos do Brasil, constituído pelo Exército e Armada, em nome da Nação:

Considerando a conveniência de regularizar o Serviço de Imigração na República, de modo que os imigrantes tenham segura garantia da efetividade dos auxílios que lhes forem prometidos para o seu estabelecimento;

Considerando que da adoção de medidas adequadas e tendentes a demonstrar o empenho e as intenções do governo, relativamente à imigração, depende o desenvolvimento da corrente imigratória e a segura aplicação dos subsídios destinados àquele serviço, ao qual se acha intimamente ligado o progresso da nação;

Considerando que faz-se conveniente a concessão de favores que animem a iniciativa particular e auxiliem o desenvolvimento das propriedades agrícolas, facilitando-lhes a aquisição de braço, de modo, porém, que seja atendida a conveniente colocação dos imigrantes, decreta:

Art. 1ํ. É inteiramente livre a entrada, nos portos da República, dos indivíduos válidos e aptos para o trabalho, que não se acharem sujeitos à ação criminal de seu país, excetuados os indígenas da Ásia ou da África, que somente mediante autorização do Congresso Nacional poderão ser admitidos de acordo com as condições que forem então estipuladas".

J) - As legislações da era Vargas são manifestamente racistas:

O Decreto-Lei $\mathrm{n}^{\mathrm{o}}$ 406, de 4 de maio de 1938, em seu artigo $1^{\mathrm{o}}$ traz exaustiva lista onde pró́be a entrada de:

"... vagabundos, ciganos e congêneres" (item II);

$\mathrm{O}$ artigo 2 - revela a "intenção de melhorar" a raça brasileira:

"O governo federal reserva-se o direito de limitar ou suspender, por motivos econômicos e sociais, a entrada de indivíduos de determinadas raças ou regime, 
ouvido o Conselho de Imigração e Colonização".

Após a Segunda Guerra Mundial, o Presidente Getúlio Vargas fixou rumos à política imigratória, mas sem afastar os motivos declarados nas legislações anteriores, principalmente o intuito de "clarear" a população. Esta intenção é tão importante quanto a própria defesa do trabalhador nacional. A preservação das características físicas européias significou para o governo uma atitude de proteção ao trabalhador nacional.

L) - O Decreto-Lei no 7.967 , de 18 de setembro de 1945, dispunha:

“O Presidente da República, usando da atribuição que the confere o artigo 180 da Constituição e considerando que se faz necessária, cessada a guerra mundial, impelir à política imigratória do Brasil uma orientação nacional e definitiva que atenda à dupla finalidade de proteger os interesses do trabalhador nacional e de desenvolver a imigração que for fator de progresso para o país, decreta:

Art. $1^{\circ}$ - Todo estrangeiro poderá entrar no Brasil, desde que satisfaça as condições estabelecidas por esta lei.

Art. $2^{o}$ - Atender-se-á, na admissão dos imigrantes, a necessidade de preservar e desenvolver, na composição étnica da população, as características mais convenientes da sua ascendência européia, assim como a defesa do trabalhador nacional".

\section{III - Constituição Brasileira de 1988}

A Constituição Brasileira de 1988, chamada a "constituição cidadã" (Deputado Constituinte Ulisses Guimarães), assegura a participação política mediante vários mecanismos de democracia semi-direta (referendo, plebiscito, iniciativa popular) e pelos representantes eleitos.

É justa, quando reconhece a luta dos negros contra a discriminação racial, e assegura entre os Direitos e Garantias Fundamentais (art. 5ㅇ, XLI e XLII):

"- A lei punirá qualquer discriminação atentatória dos direitos e liberdades fundamentais;

- A prática do racismo constitui crime inafiançável e imprescritível, sujeito à pena de reclusão, nos termos da lei."
Trata-se, quanto à aplicabilidade de normas constitucionais, de eficácia limitada. Seus efeitos são mediatos, pois dependeram do legislador para desenvolver sua aplicação a partir de legislação infraconstitucional.

$\mathrm{Na}$ atualidade, o alinhamento do movimento negro à luta dos excluídos é evidente. Presentes no movimento feminista, no movimento dos idosos, no movimento gay, lideranças negras esclarecidas, conscientes, respeitabilíssimas, chamam a atenção para a eficácia da Lei no $1776 / 89$ e as ações afirmativas. Os tempos são outros..., felizmente, e o Brasil muito deve ao Movimento Negro!

E assim, graças ao trabalho profícuo do representante do povo, o afrodescendente Carlos Alberto Cão (Deputado Federal pelo Rio de Janeiro), em 5 de janeiro de 1989, vem à luz a Lei no 7716 que tipifica como crime atos resultantes de preconceito de raça ou de cor. Posteriormente, esta lei foi aperfeiçoada pela iniciativa política de outro afrodescendente, Paulo Pahim (Deputado Federal pelo Rio Grande do Sul), aperfeiçoando a lei anterior, com as disposições da Lei n 9459 , de 13 de maio de 1997. Esta última ampliou o tipo penal (art. $1^{\circ}$ ):

"Serão punidos, na forma desta Lei, os crimes resultantes de discriminação ou preconceito de raça, cor, etnia, religião ou procedência nacional".

As políticas públicas de ações afirmativas referem-se às mesmas iniciativas mencionadas, mas, desta vez, ao detectar desigualdades, ou seja, ao encontrar segmentos da população necessitando cuidado específico, diferenciado, devem os governantes assisti-los. Tal assistência, positivamente discriminatória, encontrará suporte no "espírito da lei", ou seja, na proposta social e igualitária da Constituição Federal de 1988. Quando o constituinte assegurou a liberdade de consciência e admitiu condutas alternativas às disposições legais, ou relativizou o exercício de direitos fundamentais, sob diversas condições, possibilitou a diferenciação integradora.

a) - Acolheu a objeção de consciência (art. 5ํㅡㄴ VIII): 
"Ninguém será privado de direitos por motivo de crença religiosa ou de convicção filosófica, salvo se as invocar para eximir-se de obrigação legal a todos imposta e recusar-se a cumprir prestação fixada em lei".

O respeito e a consideração à liberdade de consciência permitiram o tratamento diferenciado, admitindo àqueles que, invocando convicção própria e contrária ao disposto em lei, a cumprissem mediante prestações alternativas. Não resta dúvida que tal providência constitucional preserva a liberdade de pensar, optar, decidir e reconhece às possíveis minorias o direito de ser e participar.

b) - Quando se relativizou o exercício de direitos fundamentais, atribuindo função social à propriedade (art. 5ㅇ, XVIII) e XXIV):

"- é garantido o direito de propriedade

- a propriedade atenderá a sua função social".

O exercício do direito de propriedade, histórica expressão da individualidade, há muito não é mais absoluto. $\mathrm{Na}$ atual ordem constitucional, o proprietário tem um compromisso com o social e normas infra-constitucionais imporão restrições ao direito de construir, à disposição de lucros empresariais, à utilização do solo urbano e rural etc. Aqui se restringe o exercício de direitos a alguns para beneficiar a sociedade. Privilegia-se o interesse social, uma vez que entre nós a concentração de renda alcança níveis insuportáveis.

c) - As inviolabilidades igualmente tradicionais, conquistas elencadas na primeira geração de direitos fundamentais, têm seu entendimento relativizado (art. 5으. XII):

" - é inviolável o sigilo da correspondência e das comunicações telegráficas, de dados e das comunicações telefônicas, salvo, no último caso, por ordem judicial, nas hipóteses e na forma que a lei estabelecer para fins de investigações criminais e instrução processual penal".

A exceção é regulamentada pela Lei no 9296, de 24 de julho de 1996 (Interceptações Telefônicas), e dependerá de ordem judicial sob segredo de justiça, além de vetar tais interceptações quando "não houver indícios razoáveis da autoria ou participação em infração penal ou a prova puder ser feita por outros meios disponíveis..." Comenta Alexandre de Moraes, alertando que, "apesar de a exceção constitucional expressa referirse somente à interceptação telefônica, entende-se que nenhuma liberdade individual é absoluta... sendo possível, respeitados certos parâmetros, a interceptação das correspondências e comunicações sempre que as liberdades públicas estiverem sendo utilizadas como instrumento de salvaguarda de práticas ilícitas".

É evidente que as finalidades sociais perseguidas pela atual ordem constitucional ensejam do mesmo modo o entendimento de que o princípio da igualdade não tem interpretação, nem aplicação absoluta.

A célebre máxima de Rui Barbosa (Oração dos Moços) no sentido de se tratar igualmente os iguais e desigualdade os desiguais, mas, conforme suas desigualdades, deve ser lembrada e o cerne da questão será objetivo colimado "assegurar, dos direitos sociais e individuais, a liberdade, a segurança, o bem estar, o desenvolvimento, a igualdade e a justiça como valores supremos de uma sociedade fraterna e sem preconceitos, fundada na harmonia social e comprometida, na ordem interna e internacional, com a solução pacífica das controvérsias" (Preâmbulo da Constituição Federal, de 1988); bem como a metodologia a ser adotada para promoção de todos.

Diante de tais objetivos, as ações afirmativas já deixam de ser novidades, principalmente sob a égide da Constituição Federal de 1988.

d) - Observe-se a igualdade entre sexos (art. 5으, I), seguida de diferenciações:

"homens e mulheres são iguais em seus direitos e obrigações, nos termos da Constituição".

Todavia esta igualdade não é retilínea, pois se reconhecem diferenciações decorrentes da natureza (licença gestante, art. 5으, XVIII), discriminações historicamente enfrentadas pelas mulheres. Daí as disposições constitucionais protetoras do mercado de trabalho da mulher, a partir de incentivos (art. 7ํㅡ, XX).

Informam órgãos da $\mathrm{ONU}$ que, se mantido o "ritmo atual de crescimento de 1\% a 2\% da mulher em cargos de direção, o mundo só terá paridade de 
representação homem - mulher daqui a 400 anos (Justificativa do Projeto de Lei n⿳⼈ㅡㄴ 783/95, então, Deputada Marta Suplicy).

Merecem atenção também as normas referentes à "família" na Constituição em vigor, quando implícita ou explicitamente se dirige às cidadãs brasileiras (art. 226, § 3으 e $4^{\circ}$ ).

"A família, base da sociedade, tem especial proteção do Estado.

Para efeito da proteção do Estado, é reconhecida a união estável entre homem e mulher como entidade familiar, devendo a Lei facilitar sua conversão em casamento.

Entende-se, também, como entidade familiar a comunidade formulada por qualquer dos pais e seus descendentes".

Ora, na nossa cultura, dificilmente encontramos "companheiros" em estado de abandono, mas sim "companheiras", mulheres que, durante décadas mantêm uma união permanecendo dedicadas ao "lar". Mas, diante de desavenças ou falecimento do companheiro, ficam expostas à miserabilidade. Reconhecidas, até passado recente, por jurisprudência impiedosa, como "prestadoras de serviços ao companheiro". Da mesma forma, rara é a família que protege a cidadania das mulheres.

Porém, o que vem chamando a atenção são as discriminações positivas, visando igualar homens e mulheres em oportunidades. Neste sentido, a participação política é fundamental.

Conforme a melhor literatura feminista, a IV Conferência Mundial de Beijing/China (setembro/1995) foi importante para efetivar entre nós políticas afirmativas, buscando dar melhores oportunidades às mulheres, estabelecendo cotas de participação na legislação eleitoral.

Em tempos de globalização, a influência das relações internacionais é decisiva, principalmente com o modelo constitucional adotado propiciando uma justiça concreta. Assim, a Lei $\mathrm{n}^{\circ}$ 9100, de 29 de setembro de 1995, dispôs sobre as eleições municipais de 1996, determinando cota de $20 \%$ para as mulheres. Seguiuse a Lei $\mathrm{n}^{\mathbf{0}} \mathbf{9 5 0 4}$, de 1 de outubro de 1997, estendendo a política de cotas para os cargos de deputados (Câmara Federal, Assembléias Legislativas e Câmara Distrital), eleitos pelo sistema proporcional. Esta última alterou também a exigência de cota mínima que passou a alcançar ambos os sexos, ou seja, 30\% no mínimo e $70 \%$ no máximo, tanto para homens como para mulheres.

O movimento feminista, através de suas entidades, promoveu debates e apresentações na mídia, com resultados animadores.

e) - Exemplo expressivo de discriminação positiva no âmbito da própria Constituição Federal é o tratamento diferenciado destinado aos cidadãos portadores de deficiência. Realidade enfrentada mediante ações afirmativas com a efetivação dos direitos aos cidadãos, que, sendo portadores de necessidades especiais, nunca haviam recebido atenção dos governos. O Brasil simplesmente perdeu talentos, as pessoas que necessitam de cuidados especiais, na verdade, eram ignoradas, vitimadas pela omissão.

O legislador constituinte elencou a proteção aos cidadãos portadores de necessidades especiais entre as competências legislativas concorrentes (art. 24, XIV, § $1^{\mathrm{O}}$ ):

"Compete à União, aos Estados e ao Distrito Federal legislar concorrentes sobre:

"proteção e integração das pessoas portadoras de deficiência”".

"No âmbito da legislação concorrente, a competência da União limitar-se-á a estabelecer normas gerais".

A Lei no 7853 , de 24 de outubro de 1989, dispôs sobre o apoio e a integração social, instituindo inclusive a Coordenadoria Nacional para Integração da Pessoa Portadora de Deficiência (CORDE), bem como a tutela jurisdicional de interesses coletivos ou difusos de pessoas em tais condições. É importante notar o reconhecimento dos cidadãos portadores de necessidades especiais em juízo pelo Ministério Público e por associações através de ações coletivas (mandado de segurança coletivo, ação civil pública).

As previsões constitucionais quanto ao exercício de direitos humanos não podem ser interpretadas separadamente, não há exercício de 
direitos de maneira autônoma. A consagração da dignidade humana exige que seja propiciado a todos o exercício de todos os direitos. Como assegurar a vida, sem a educação, o trabalho, a saúde etc.

Assim, a Constituição Federal, ao disciplinar a Administração Pública, determina (art. 37, VIII):

"A administração pública direta e indireta de qualquer dos Poderes da União, dos Estados, do Distrito Federal e dos Municípios, obedecerá aos princípios da legalidade, impessoalidade, moralidade, publicidade e eficiência e, também, ao seguinte:

'a Lei reservará percentual dos cargos e empregos públicos para as pessoas portadoras de deficiência e definirá os critérios de sua admissão'".

Este expressivo tratamento discriminatório inicia um processo de inclusão das pessoas portadoras de necessidades especiais, tem o objetivo de efetivar-lhes o exercício de direitos e melhor qualidade de vida. Trata-se de norma constitucional de eficácia limitada, ou seja, seu vigor para gerar efeitos dependerá de leis específicas com a determinação da porcentagem de vagas.

Regulamentando a Lei no 7853, de 24 de outubro de 1989, veio à luz o Decreto no 3289 , de 20 de dezembro de 1999, estabelecendo percentual de empregos nas empresas e concursos públicos:

"Art. 36 - A empresa com cem ou mais empregados está obrigada a preencher de dois a cinco por cento de seus cargos com beneficiários da Previdência Social reabilitados ou com pessoa portadora de deficiência habilitada, na seguinte proporção:

I - até duzentos empregados, dois por cento;

II - de duzentos e um a quinhentos, três por cento;

III - de quinhentos e um a mil empregados, quatro por cento;

IV - mais de mil funcionários, cinco por cento;"

"Art. 37 - fica assegurado à pessoa portadora de deficiência o direito de se inscrever em concurso público, em igualdade de condições com os demais candidatos, para provimento de cargo, cujas atribuições sejam compatíveis com a deficiência de que é portador".

$\mathrm{Na}$ administração pública paulista, o assunto vem disciplinado pela Lei Complementar $\mathrm{n}^{\mathbf{0}}$ 683, de 18 de setembro de 1992:

"Art. 1 - o provimento de cargos e empregos públicos, nos órgãos e entidades da administração direta, indireta e funcional, obedecido o princípio do concurso público de provas ou de provas e títulos, far-se-á com reserva de até 5\% (cinco por cento) para pessoas portadoras de deficiência.

$\S 1^{\circ}$ - Para gozar dos benefícios da Lei Complementar, os portadores de deficiência deverão declarar, no ato de inscrição ao concurso público, o grau de incapacidade que apresentam".

E, no âmbito da Administração do Município de São Paulo, temos a Lei no 11.276 , de 12 de novembro de 1992:

"Art. 3 - nos concursos públicos, será reservado um percentual de até 5\% (cinco por cento) de cargos e empregos públicos para pessoas portadoras de deficiencias compatíveis com a atividade a ser exercida, nos termos do disposto no artigo $1^{\circ}$ desta Lei".

"Art. 4- O percentual, a que se refere o artigo anterior, será fixado pelo Secretário Municipal da Administração, mediante proposta fundamentada da comissão de cada concurso público".

"Art. 5․ - Os candidatos inscritos em conformidade com esta Lei prestarão o concurso público juntamente com os demais candidatos, obedecidas as mesmas exigências para o cargo ou emprego, em provas iguais quanto ao conteúdo, sendo classificados em separado, para efeitos de preenchimento de vagas pertinentes".

"§ $1^{\circ}$ - Serão chamados proporcionalmente os candidatos deficientes e os demais, até o preenchimento das vagas reservadas".

"§ 2-. Quando o número de candidatos habilitados nos termos desta Lei for inferior ao número de vagas reservadas, estas reverterão para os demais candidatos habilitados".

"§ 30 - Quando o número de candidatos habilitados nos termos desta Lei for superior ao número de vagas reservadas, os deficientes passarão a integrar a classificação geral, para efeito de ingresso".

Busca-se com tais providências constitucionais integrar os cidadãos, conforme condições naturais, sociais e econômicas que apresentem. 


\section{Conclusões}

As omissões de governos, bem como a construção há cinco séculos de um direito manifestamente racista e voltado aos interesses de elites mantêm a exclusão e sobretudo a discriminação racial no mercado de trabalho.

O rompimento de realidades tão injustas de- penderá do aprimoramento da participação política, da ingerência dos cidadãos na res publicae com adoção de mecanismos controladores e fiscalizadores dos mandatos políticos e inclusive dos atos jurisdicionais.

Aí sim, a partir da gestão popular, teremos reformas reais e um direito compromissado com o social.

\section{REFERÊNCIAS BIBLIOGRÁFICAS}

AFFONSO, Ruy. A primeira revolução social brasileira: 1978. Rio de Janeiro: Laébmmert, 1.970.

AMADO, Janaina. Contribuição ao estudo da imigração alemã no Rio Grande do Sul, São Leopoldo, 1.824 - 1.874. Revista Ciência e Cultura. São Paulo, 19(7): 735-7. jul. 1977.

ARARIPE, Tristão de Alencar. Código Civil Brasileiro, ou Leis Civis do Brasil. Rio de Janeiro: Laémmert, 1885.

ARAÚJO, Clara. Potencialidade e limites da política de cotas no Brasil. Revista Estudos Feministas, v. 9. Centro de Filosofia e Ciências Humanas - UFSC. Centro de Comunicação e Expressão - UFSC, p. 231 - 252, 1998.

BANDECHI, Brasil. Legislação básica sobre a escravidão africana no Brasil. Separata da Revista de História, 89, 1972.

BESAVE, Agustín. La dimension juridica del hombre; fundamentos antropológicos de la filosofia del derecho. Revista de Informação Legislativa. Brasília, Senado Federal, 9 (36): 31-6, out./dez.

BRASIL, Leis decretos etc. Colleção das leis do Império no Brasil. 2. ed. Ouro Preto: Tip. Silva, 1835, v. 3.

BRASIL, leis, decretos etc Constituição da República Federativa do Brasil, 1998. São Paulo: Saraiva, 2003.

BUENO, José Antonio Pimenta. Direito público brasileiro e analyse da Constituição do Império. Rio de Janeiro: Villeneeue, 1857.

CAMARGO, Oswaldo. O negro escrito. Apontamentos sobre a presença do negro na literatura brasileira. São Paulo: IMESP, 1987.

CANOTILHO, José Joaquim Gomes. Constituição dirigente e vinculação do legislador, contributo para a compreensão das normas constitucionais programáticas. Coimbra Ed. Ltda., reimpressão, 1994.

CAVALLEIRO, Eliane. Do silêncio do lar ao silêncio escolar - racismo, preconceito e discriminação na educação infantil. São Paulo: Contexto, 2000.

CHIAVENATO, Julio José. O negro no Brasil: da senzala à Guerra do Paraguai. São Paulo: Brasiliense, 1980.

DALLARI, Dalmo de Abreu. Elementos de Teoria Geral do Estado. São Paulo: Saraiva, 2002.

. O futuro do estado. São Paulo: Saraiva, 1972.

. Viver em Sociedade. São Paulo: Moderna, 1985.

DEMORO, Luís. Coordenação de leis de imigração e colonização do Brasil. Rio de Janeiro: Dep. Est. Plan. Inst. Nac. de Imigração e Colonização, 1960.

FERNANDES, Florestan; BASTILDE, Roger. Brancos e negros em São Paulo. 3. ed. São Paulo: Nacional, 1971.

FERREIRA FILHO, Manoel Gonçalves. Comentários à Constituição Brasileira de 1988. São Paulo: Saraiva, 1990.

GROSSI, Miriam Pillar et al. Transformando a diferença: as mulheres na política. Revista Estudos Feministas. v. 4. Centro de Filosofia e Ciências Humanas - UFSC. Centro de Comunicação e Expressão - UFSC, p. 167 - 206, 1998.

HENRIQUES, Ricardo. Desigualdade racial no Brasil: evolução das condições de vida na década de 90 . Instituto de Pesquisa Econômica Aplicada (IPEA). Texto para discussão no 807, 2001.

JONES, James M.Racismo e preconceito. Tradução Dante Moreira Leite. São Paulo: Bildcher, EDUSP, 1973.

MALHEIRO, Agostinho Marques Perdigão. Escravidão no Brasil: ensaio histórico, jurídico, social. Rio de Janeiro: Nacional, 1866. MELLO, Celso Antonio Bandeira de. O conteúdo jurídico do princípio de igualdade. São Paulo: Revista dos Tribunais, 1978.

MENEZES, Paulo Lucena. Ação afirmativa (Affirmative action) no direito norte-americano. São Paulo: Revista dos tribunais, 2001. MORAES, Alexandre. Constituição do Brasil interpretada. São Paulo: Atlas, 2002.

MOURA, Clóvis Steiger de Assis. Brasil: raízes do protesto negro. São Paulo: Global, 1983.

NASCIMENTO, Abdias do. O genocídio do negro brasileiro: processo de um racismo mascarado. Rio de Janeiro: Paz e Terra, 1978. OLIVEIRA, Lúcia Helena Garcia; PROCARO, Rosa Maria; ARAÚJO, Tereza Cristina N. O lugar do negro na força de trabalho.

Fundação Instituto Brasileiro de Geografia e Estatística. Rio de Janeiro: IBGE, 1981.

POCHMANN, Márcio. Atlas da exclusão social - os ricos no Brasil. São Paulo: Cortez, 2004. 
PRUDENTE, Eunice Aparecida de Jesus. Preconceito racial e igualdade jurídica no Brasil - a cidadania negra em questão. Campinas: Julex, 1989.

. Direito à personalidade integral - cidadania plena. Tese (Doutorado). Orientador Prof. Dr. Dalmo de Abreu Dallari. FADUSP, São Paulo, 1996.

ROCHA, Carmen Lucia Antunes. O conteúdo democrático do princípio da igualdade jurídica. Revista de Informação Legislativa. n. 131, p. $283-295,1996$.

SILVA, José Afonso. Curso de Direito Constitucional Positivo. São Paulo: Malheiros, 1999.

SKIDMORE, Thomas Elliot. Preto no branco: raça e nacionalidade no pensamento brasileiro. Tradução Raul de Sá Barbosa. Rio de Janeiro: Paz e Terra, 1976.

VIANNA, Francisco José Oliveira. Evolução do povo brasileiro. São Paulo: Monteiro Lobato, [s.d.]. 